\title{
Dr Serban C. Moldoveanu, Recipient of the 2012 Tobacco Science Research Conference Lifetime Achievement Award
}

\author{
Laudation to the award given by \\ Anthony R. Gerardi \\ RJ Reynolds, 950 Reynolds Blvd, Winston-Salem, NC 27105, USA
}

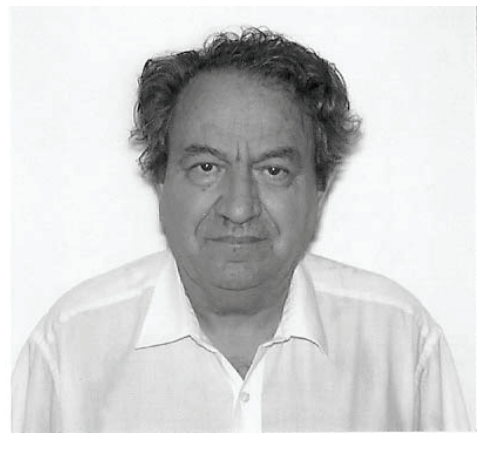

Serban Moldoveanu has contributed extensively to the understanding of tobacco chemistry in a variety of ways ranging from analytical methods development to the comprehensive study of pyrolysis products of compounds and polymers found in tobacco.

This body of work has underwritten the fundamental understanding of tobacco product chemistry and aided in the development of many potentially reduced toxicant, harm, and exposure products and prototypes. Dr Moldoveanu's advancement of scientific knowledge in the tobacco arena has been thoroughly documented in over 120 peer reviewed scientific articles, several patents, and various presentations at scientific conferences, including over 40 presentations at the Tobacco Science Research Conference. Though there are many hallmarks of scientific achievement to be noted in his lengthy career, the most noteworthy would be his 5 published books which provide some of the most complete studies on pyrolysis and analytical techniques by a tobacco scientist. His body of work has been referenced numerous times by scientists all over the world. The overall magnitude and breadth of scientific composition is his magnum opus, and rarely achieved by one outside of academia.

Dr Moldoveanu has had several careers outside of tobacco since his graduate education in Romania, including various professorships at universities across the USA. Through these experiences, he has mastered the art of scientific mentorship and thus facilitated the development of many young scientists throughout his 26 year career as an industrial tobacco scientist. He embodies every ideal associated with a scientist of the highest caliber: thoughtful, skeptical, collaborative, logical, mentor, wise, intuitive.

Dr Moldoveanu began his career as a post-doctoral fellow at the University of Bucharest (Romania), from which he obtained his PhD in Chemistry and Master in Mathematics. He was later a professor at the same university for a number of years before moving from the communist bloc country to the United States to obtain a better life for himself and his family. His first position in the USA was as a visiting professor at the University of Georgia-Athens (UGA) in the Department of Chemistry. His primary duties were teaching classes and labs. However, he also performed innovative research on developing new electrochemical detectors for HPLC and working on numerical solutions for convective diffusion. After this position ended, he briefly worked in industry as a scientist for Dowell-Schlumberger performing various analyses on oildrilling related materials.

Dr Moldoveanu has held several positions at Brown and Williamson Tobacco Company and more recently RJ Reynolds Tobacco Company. He has been everything from a research scientist to a group manager and in between. His current position is Principal Scientist at RJ Reynolds.

Dr Moldoveanu started working in the tobacco industry at Brown and Williamson Tobacco Company as a research scientist in 1986. Already a seasoned scientist, he began to make an immediate impact with pioneering method development using GC-MS, GC-GC/MS and LC-MS techniques to study sugars, amino acids and various other constituents 
so as to develop blend modeling algorithms for theoretical product development. The use of informatics in conjunction with data from state of the art analytical methods was a very necessary tool in the ever evolving tobacco science landscape.

His research interests grew as he ingested more tobacco specific information and began the pursuit of a comprehensive reference book comprised of pyrolysis information he both generated and gathered. Dr Moldoveanu wanted to understand the complete relationship between precursor molecules found in tobacco and the compounds they produced during combustion and pyrolysis. This led to his first book, Analytical Pyrolysis of Natural Organic Polymers, published in 1998. This book and the subsequent books to follow provided insight into the product/precursor relationship that were never before seen. His unique experiments coupled to reviewed literature have provided the industry with tools to better understand tobacco smoke chemistry.

In order to fill analytical methods gaps, Dr Moldoveanu collaborated, developed and published many methods, which are still used to this day in regulatory labs across the industry. Among the analyses he developed for tobacco and smoke were methods to determine Polycyclic Aromatic Hydrocarbons (PAH), pH of whole smoke, aromatic amines, carbolines, carbonyls, phenols, Selected Volatile Organics (SVO), humectants, triglycerides, phytol, solanesol, sugars, amino acids and proteins, acrylamide, and many others. Dr Moldoveanu used novel sample clean-up, separation and detection methods and many of these were published in high tier journals such as the Journal of Chromatography, Carbohydrate Research, and the Journal of Analytical and Applied Pyrolysis. More recently, Dr Moldoveanu helped pioneer the study of exhaled breath condensate analytes to help better understand the deposition of compounds during the actual use of a smoking article. This work was crucial in supporting various yield in use models and studies.

Dr Moldoveanu has spent his career collaborating with various institutions of higher learning and giving back to the scientific community. As mentioned, he has been a mentor to many young tobacco scientists. Also, his professional involvement in the scientific community is exemplary. He serves as a reviewer for several journals including the Journal of Chromatography A, Analytica Chimica Acta, Talanta, Journal of Analytical and Applied Pyrolysis, Beiträge zur Tabakforschung International, and Flavor and Fragrances Journal, to name a few. He is an active member of the American Chemical Society and serves on the board of the Journal of Analytical Methods in Chemistry. Serban has 2 sons, a step son, 4 grandchildren and is married to his lovely wife Carol. They are a wonderful couple and a joy to be around. He loves his family very much and visits them quite often.

It is rare to find a scientist in an industrial setting who has accomplished and published as much as Serban through what might be considered his second career. He respects everyone he meets and shows his interest in a meaningful and genuinely appreciative manner. His scientific merit alone sets him apart, but combined with his humanity and lifetime of experience he shares through anecdotes of wisdom truly make him deserving of such an honor as is the TSRC Lifetime Achievement Award.

Tonight, it is my pleasure and honor to present to you the 2012 Tobacco Science Research Conference's Lifetime Achievement Award winner. He is a colleague, friend, mentor, and someone for whom I have the upmost respect and admiration. He is a scientific treasure to my company and to our tobacco community as a whole. Ladies and gentlemen, I am so proud to present to you the 2012 TSRC Lifetime Achievement Award winner - Dr Serban Moldoveanu.

Corresponding author:

Anthony R. Gerardi, Ph.D.

Senior Scientist

RJ Reynolds

950 Reynolds Blvd.

Winston-Salem, NC 27105

USA

E-mail: GerardA@RJRT.com 